\title{
A AUSÊNCIA DOS PAIS E SUAS CONSEQUÊNCIAS NA FORMAÇÃO DAS HABILIDADES SOCIAIS NA ADOLESCÊNCIA
}

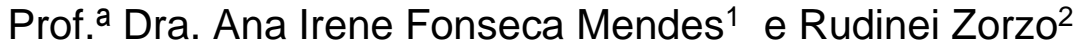 \\ Não é um fenômeno dos marginalizados sociais, das classes baixas, \\ de um mundo distante. \\ Os filhos órfãos são uma legião e estão entre nós, ao nosso lado. \\ Sergio Sinay
}

\begin{abstract}
RESUMO: Vive-se um momento histórico no qual as relações deixam de ser pautadas pelo amor e dão lugar a interesses, sejam elas familiares ou de amizade, este desvio de foco do amor faz com que o desenvolvimento das habilidades sociais dos adolescentes e jovens esteja comprometido, fazendo-os sentir essa falta. $O$ tempo da adolescência é o tempo da busca de afirmação. Afirmação com relação a si, aos pais e, por isso a busca por um grupo de amigos, da mesma forma, o grupo de amigos pode também exercer influências negativas, levando a comportamentos antissociais e de risco, como o uso de substâncias, por exemplo. Com famílias fragilizadas e cada vez menos ativas e participantes cada vez fica mais difícil a tarefa dos adolescentes adquirirem habilidades sociais. Pois, por mais que a identificação do adolescente se dê mais com seus pares o papel da família é fundamental para a transmissão dos valores e formação do caráter.
\end{abstract}

Palavras-chave: Família. Ausência dos pais. Habilidades sociais. Lacunas das habilidades sociais. Limites.

\footnotetext{
1 Possui graduação em Psicologia (1997) pela Faculdade de Filosofia Ciências e Letras de Ribeirão Preto - USP (FFCLRP-USP), Mestrado (2001) e Doutorado (2008) pelo programa de Pós-Graduação em Psicobiologia da FFCLRP-USP. Atualmente é Supervisora de Estágio e Colaboradora de Pesquisa do Laboratório de Pesquisa e Intervenção Cognitivo-Comportamental (LaPICC) da FFCLRP ? USP. Foi Coordenadora do Ambulatório de Terapia Cognitivo-Comportamental no HCFMRP-USP (de 2014 a 2018, em atuação conjunta com os ambulatórios de Transtornos de Ansiedade, Transtornos de Humor, Esquizofrenia, e Álcool e Drogas). Professora convidada dos Cursos de Especialização em Terapia Cognitivo-Comportamental do Cognitivo-IWP. Conteudista e tutora do EAD do curso de especialização em Terapia Cognitivo-Comportamental da UNIARA. Atua em clínica particular como Terapeuta Cognitivo-Comportamental atendendo crianças, adolescentes e adultos. Possui Certificação como Terapeuta Cognitivo-Comportamental pela Federação Brasileira de Terapias Cognitivas-FBTC.

${ }^{2}$ Graduado em Filosofia pela Universidade em Caxias do Sul (UCS-2006), Graduado em Teologia pela Pontifícia Universidade Católica do Rio Grande do Sul (PUCRS-2010), Pós-graduado em Psicologia, desenvolvimento humano e habilidade sociais pela Universidade de Araraquara (UNIARA-2016), Mestre em Resolução de Conflitos e Mediação - Universidad Europea del Atlántico (UNEATLÁNTICO2018) , Mestre em Gestão Estratégica, especialidade: Gerenciamento - Universidad Internacional Iberoamericana (UNINI-2018) e Cursa Pós-Graduação em Psicopedagogia Institucional e Clínica na Braz Cubas (BRAZ CUBAS-2019...). Já atuou como professor de Filosofia, Sociologia e Ensino Religioso para Ensino Médio. Atualmente é coordenador do serviço de evangelização da juventude da regional Sul 3 e coordenador de comunicação - Conferência Nacional dos Bispos do Brasil, além de professor de Metodologia Científica no Colégio Mutirão de São Marcos/RS. E-mail: rudineizorzo@gmail.com
} 
ABSTRACT: A historic moment one lives in which relationships are no longer guided by love and give rise to concerns, whether family or friends, this shift of focus of love makes the development of social skills of adolescents and young people is compromised, making them feel this lack. The teenage time is the time of the search statement. Statement with respect to themselves, their parents, and so the search for a group of friends, the same way, the group of friends can also exert negative influences, leading to antisocial and risk behaviors such as substance use, for example . With vulnerable families and less active participants and each time gets more difficult the task of adolescents acquire social skills. For as much as the teen's identification to give more to their peers the role of the family is essential for the transmission of values and character formation.

Keywords: Family. Absence of parents. Social skills. Gaps in social skills. Limits.

\section{INTRODUÇÃO}

As relações humanas, marcadas pela evolução tecnológica e científica e por certo distanciamento afetivo, se tornam cada vez mais complexas diante da necessidade de estabelecer relações interpessoais mais satisfatórias, de se adaptar aos diferentes contextos e às demandas pertinentes a cada faixa etária (OLIVEIRA; SILVA, 2013).

As relações interpessoais, diante de tudo isso, deixam de ser pautadas pelo amor e dão lugar a interesses, sejam elas familiares ou de amizade (BAUMAN, 2004). A ausência física ou emocional da figura paterna causa um desvio de foco do amor fazendo com que o desenvolvimento das habilidades sociais dos adolescentes e jovens esteja comprometido, fazendo-os sentir essa falta (SINAY, 2015).

Roudinesco, citado por Cúnico S. e Arpini D. (2014), traça as três fases que a figura paterna já viveu ao longo da história:

A primeira delas diz respeito à família dita tradicional, em que o principal objetivo era a transmissão de patrimônio através de casamentos arranjados pelos pais, em uma clara submissão da família frente à autoridade patriarcal. Na segunda fase, encontra-se a família moderna, fundada no amor romântico e que sancionava a reciprocidade dos sentimentos através do casamento. Aqui, a atribuição da autoridade era dividida entre o Estado e os pais, de um lado, e entre os pais e as mães, de outro, já que essa família valorizava a divisão do trabalho entre os cônjuges e considerava a educação dos filhos dever do Estado. A partir dos anos 60, impõe-se a terceira fase, a chamada família contemporânea ou pós-moderna, na qual dois indivíduos buscam relações íntimas e realização sexual ao longo de uma relação nem sempre duradoura. À medida que as separações, os divórcios e as recomposições conjugais vão aumentando, a transmissão da autoridade vai tornando-se 
cada vez mais complexa. (ROUDINESCO, Apud. CÚNICO S. e ARPINI D., 2014)

É preciso compreender primeiro o que é família e qual a função da figura paterna para depois adentrar-se no campo das habilidades sociais, por isso este projeto inicia com um resgate histórico da compreensão de família e da participação da figura do homem na mesma.

Del Prette e Del Prette (2013) com sua vasta experiência na pesquisa das habilidades sociais afirmam que estas podem ser definidas como o conjunto dos desempenhos apresentados pelo indivíduo diante das demandas de uma situação interpessoal. Essas habilidades são aprendidas e as demandas para o seu desempenho variam em função do estágio de desenvolvimento do indivíduo e de variáveis situacional-culturais (DEL PRETTE; DEL PRETTE, 2013).

A ausência paterna tem potencial para gerar conflitos no desenvolvimento psicológico da criança. A influência da ausência paterna no desenvolvimento cognitivo e em distúrbios do comportamento aponta para uma má formação das habilidades sociais (LOPES; PAULA, 2011)

Ao longo do trabalho faz-se a diferenciação entre ausência física e emocional, pois muitos pais formam família, todavia não são família, estando assim distante emocionalmente dos filhos, esse afastamento também gera consequências para o desenvolvimento das Habilidades Sociais. Por outro lado, tem-se a ausência física da figura paterna em muitas famílias, sobre isso Benczik escreve:

as crianças que têm pai presente apresentam nível de autoestima superior àquelas que têm pai ausente, com o qual não convivem. $O$ pai é um pilar muito importante no desenvolvimento de qualquer criança. Quanto maior é a participação e o envolvimento do pai no crescimento e na educação da criança, melhor é a qualidade da relação que se estabelece entre ambos. (BENCZIK, E., 2011).

A importância da busca por compreender o que representa para a formação das habilidades sociais numa criança a ausência dos pais ou a presença física, todavia ausência sentimental, faz ser válida pesquisa deste tema. Assim como Del Prette reflete que nenhuma criança nasce com a tendência de pregar ou agir de forma dissimulada, mas é influenciada pelo meio, pela família (DEL PRETTE; DEL PRETTE, 2013). A falha em estabelecer limites, a relação conflitiva com os filhos ou a ausência sentimental ou física dos pais são algumas das condições que contribuem para o estabelecimento de estilos não habilidosos dos quais pais e professores tanto se queixam. 
Esta pesquisa visa uma melhor compreensão do adolescente que chega à escola nas séries iniciais ou do jovem que chega ao ensino fundamental e médio ainda carente de habilidades sociais e com problemas no seu desenvolvimento. Não pretende ser uma resposta a todas as perguntas, todavia pretende dar um panorama geral de como a ausência paterna - seja ela por morte do cônjuge, pela ausência física ou emocional do mesmo - causam lacunas na transmissão e aquisição das Habilidades Sociais.

Vive-se numa sociedade em constante mudança, tudo o que hoje era moderno amanhã pode se tornar obsoleto. Isso afeta diretamente nossas famílias que, por vezes não sabem lidar com seus filhos e acabam ausentando-se. Este trabalho buscará analisar as consequências da falta dos pais em casa. Divide-se essa falta em física e afetiva ou emocionalmente, pois sabe-se que muitos pais estão presentes fisicamente em suas casas, todavia estão ausentes emocionalmente de seus filhos e isso gera consequências no tocante as habilidades sociais dos mesmos. Ao posso que, se buscará identificar se essa falta realmente afeta diretamente os adolescentes e se eles são capazes de adquirir as habilidades sociais defasadas com o passar do tempo. Por isso, se fará uma tentativa de descrever as habilidades sociais na adolescência, como são aprendidas e quais as consequências da falta das mesmas, analisando se essa consequência está relacionada a ausência dos pais.

\section{RESULTADOS E DISCUSSÃO}

A partir das buscas nas bases de dados nacionais foram selecionados os artigos de revisão bibliográfica ou de relato de experiência, publicados no período de 2003 a 2016, em língua portuguesa, que verificaram a participação paterna em adolescentes e suas implicâncias no tocante as habilidades sociais.

Foram selecionados 13 (treze) artigos, sendo 3 (três) artigos de relato de caso, 3 (três) de estudo comparativo, 3 (três) sobre as habilidades sócias, 3 (três) de reflexões sobre o tema e 1 (um) de análise de literatura. Além de 4 (quatro) livros impressos. De forma que no período de 2004 a 2009 são 6 (seis) artigos, e de 2010 a 2014 são 7 (sete) artigos encontrados. Os livros são dos anos de 2003, 2009, 2013 e um mais recente de 2015. Conforme demonstrado no quadro 1. 
Quadro 1 - Características dos artigos e livros encontrados.

\begin{tabular}{|c|c|}
\hline es) & objetivo(s) \\
\hline $\begin{array}{l}2015 \\
\text { Sinay }\end{array}$ & $\begin{array}{l}\text { Título: A sociedade dos filhos órfãos: quando pais e mães } \\
\text { abandonam suas responsabilidades. } \\
\text { Objetivo: Busca analisar a falta que os pais fazem na vida das } \\
\text { crianças e adolescentes. }\end{array}$ \\
\hline $\begin{array}{l}2014 \\
\text { Cúnico } \\
\text { Arpini }\end{array}$ & $\begin{array}{l}\text { Título: Não Basta Gerar, Tem que Participar? - Um Estudo Sobre a } \\
\text { Ausência Paterna } \\
\text { Objetivo: O presente estudo buscou conhecer, por meio de uma } \\
\text { abordagem qualitativa, quais as possíveis razões para a ausência } \\
\text { paterna na vida dos filhos após o rompimento conjugal. }\end{array}$ \\
\hline $\begin{array}{l}2013 \\
\text { Oliveira } \\
\text { Silva }\end{array}$ & $\begin{array}{l}\text { Título: Habilidades sociais: um estudo bibliométrico sobre os avanços } \\
\text { deste campo no Brasil. } \\
\text { Objetivo: caracterizar o campo das habilidades sociais no Brasil, a } \\
\text { partir de uma pesquisa bibliométrica, ou seja, aquela que utiliza-se } \\
\text { de dados estatísticos ou matemáticos para avaliar o estado de um } \\
\text { determinado campo da ciência. }\end{array}$ \\
\hline $\begin{array}{l}2013 \text { Del } \\
\text { Prette e Del } \\
\text { Prette }\end{array}$ & $\begin{array}{l}\text { Título: Psicologia das Habilidades sociais na infância: Teoria e } \\
\text { Prática } \\
\text { Objetivo: busca apresentar a psicologia das habilidades sociais não } \\
\text { somente na teoria, mas também na prática, dando dicas de aplicação } \\
\text { do estudo. }\end{array}$ \\
\hline $\begin{array}{l}2012 \\
\text { Patias } \\
\text { Al. }\end{array}$ & $\begin{array}{l}\text { Título: Práticas educativas parentais e gestação na adolescência: } \\
\text { comparando as experiências da gestante adolescente e da } \\
\text { adolescente sem experiência de gestação. } \\
\text { Objetivo: comparar a experiência de duas adolescentes (uma grávida } \\
\text { e outra sem experiência de gestação), no que se refere às práticas } \\
\text { educativas parentais vividas no contexto familiar. }\end{array}$ \\
\hline $\begin{array}{l}2011 \\
\text { Lopes e de } \\
\text { Paula }\end{array}$ & $\begin{array}{l}\text { Título: A importância da figura paterna no processo de escolha } \\
\text { profissional: um estudo comparativo entre jovens universitários } \\
\text { Objetivo: verificar se o jovem que não contou com a presença do pai } \\
\text { durante seu desenvolvimento elegeu alguma figura substituta e se a } \\
\text { ausência paterna trouxe implicações em sua escolha profissional. }\end{array}$ \\
\hline
\end{tabular}




\begin{tabular}{|c|c|}
\hline $\begin{array}{l}2011 \\
\text { Benczik }\end{array}$ & $\begin{array}{l}\text { Título: A importância da figura paterna para o desenvolvimento } \\
\text { infantil } \\
\text { Objetivo: trazer à luz algumas reflexões sobre o atual papel do pai, } \\
\text { tanto para o filho, quanto para a família, bem como a sua grande } \\
\text { importância na estruturação psíquica e no desenvolvimento social e } \\
\text { cognitivo da criança. }\end{array}$ \\
\hline $\begin{array}{l}2010 \\
\text { Sganzerla e } \\
\text { Levandows } \\
\text { ki }\end{array}$ & $\begin{array}{l}\text { Título: Ausência paterna e suas repercussões para o adolescente: } \\
\text { análise da literatura } \\
\text { Objetivo: Este estudo objetivou analisar estudos empíricos } \\
\text { publicados entre } 1998 \text { a } 2008 \text { sobre a ausência paterna e suas } \\
\text { repercussões para o adolescente. Foi realizada uma busca em quatro } \\
\text { bases de dados (Psyclnfo, LILACS, Scielo e Pubmed), utilizando } \\
\text { como termos descritores: ausência paterna, paternidade, pais não } \\
\text { residentes, relações familiares e adolescência. }\end{array}$ \\
\hline $\begin{array}{l}2009 \\
\text { Emidio et. } \\
\text { Al. }\end{array}$ & $\begin{array}{l}\text { Título: Terapia infantil e treino de pais em um caso de agressividade. } \\
\text { Objetivo: avaliar o efeito do treino de pais e de uma intervenção } \\
\text { comportamental em padrões comportamentais agressivos de uma } \\
\text { criança. }\end{array}$ \\
\hline $\begin{array}{l}2009 \\
\text { Silva } \\
\text { Murta }\end{array}$ & $\begin{array}{l}\text { Título: Treinamento de Habilidades Sociais para Adolescentes: Uma } \\
\text { Experiência no Programa de Atenção Integral à Família (PAIF). } \\
\text { Objetivo: Este artigo apresenta uma avaliação do processo de um } \\
\text { programa de habilidades sociais para adolescentes vinculados ao } \\
\text { Programa de Atenção Integral à Família (PAIF). }\end{array}$ \\
\hline $\begin{array}{l}2009 \text { Del } \\
\text { Prette e Del } \\
\text { Prette }\end{array}$ & $\begin{array}{l}\text { Título: Psicologia das habilidades sociais: diversidade teórica e suas } \\
\text { implicações } \\
\text { Objetivo: aprofundar ainda mais o conhecimento sobre as } \\
\text { habilidades sociais, }\end{array}$ \\
\hline $\begin{array}{l}2008 \\
\text { Monticelli }\end{array}$ & $\begin{array}{l}\text { Título: Efeitos da ausência paterna na aprendizagem. } \\
\text { Objetivo: O texto parte de uma situação de ensino envolvendo gênero } \\
\text { dos substantivos como modo de abordar outra compreensão do erro } \\
\text { no processo de aprendizagem. }\end{array}$ \\
\hline 2008 & Título: Um sistema de categorias de habilidades sociais educativas. \\
\hline
\end{tabular}




\begin{tabular}{|c|c|}
\hline $\begin{array}{l}\text { Del Prette e } \\
\text { Del Prette }\end{array}$ & $\begin{array}{l}\text { Objetivo: apresenta um Sistema de Habilidades Sociais Educativas } \\
\text { (SHSE), com classes e subclasses aplicáveis à tarefa de pais, } \\
\text { professores e demais pessoas comprometidas com a promoção do } \\
\text { desenvolvimento e aprendizagem do outro. }\end{array}$ \\
\hline $\begin{array}{l}2006 \\
\text { Bandeira et. } \\
\text { All }\end{array}$ & $\begin{array}{l}\text { Título: Habilidades sociais e variáveis sociodemográficas em } \\
\text { estudantes do ensino fundamental. } \\
\text { Objetivo: Estudo sobre a importância e frequência das habilidades } \\
\text { sociais em relação a variáveis sociodemográficas, com } 257 \\
\text { estudantes, de } 1^{\text {a }} \text { a } 4 \text { a série do ensino fundamental. Para avaliar } \\
\text { habilidades sociais, utilizou-se o Sistema de Avaliação de } \\
\text { Habilidades Sociais (SSRS) e, para o nível socioeconômico, o } \\
\text { Critério Brasil. Participaram, como informantes, } 185 \text { pais e } 12 \\
\text { professoras. }\end{array}$ \\
\hline $\begin{array}{l}2004 \\
\text { Eizirik e } \\
\text { Bergmann }\end{array}$ & $\begin{array}{l}\text { Título: Ausência paterna e sua repercussão no desenvolvimento da } \\
\text { criança e do adolescente: um relato de caso } \\
\text { Objetivo: revisão bibliográfica a respeito do tema e um relato de caso } \\
\text { específico. }\end{array}$ \\
\hline $\begin{array}{l}2003 \\
\text { Gadotti }\end{array}$ & $\begin{array}{l}\text { Título: Dialética do amor paterno. } \\
\text { Objetivo: de forma clara e direta com análise de sua vida como pai o } \\
\text { autor busca mostrar atrás de ideias, com uma pitada de amor, a } \\
\text { importância social de assumir o papel de pai numa família e a } \\
\text { consequência benéfica desta ação. }\end{array}$ \\
\hline
\end{tabular}

Fonte: Elaboração própria, com base nos dados coletados.

Com base na pesquisa bibliográfica (quadro 1), percebe-se que a maior participação do pai na criação e no cuidado com os filhos tem influência positiva tanto na vida da criança quanto na vida do adolescente. Através dos artigos encontrados percebe-se que os filhos se tornam mais felizes e bem-educados, com uma gama maior de habilidades sociais quando seus pais participam mais ativamente e, dede cedo, nas tarefas com as crianças. Quando se fala em participação na educação da criança se fala em participação ativa e afetiva, pois muitos pais estão presentes fisicamente, mas não emocionalmente da vida de seus filhos (SINAY, 2015).

Del Prette e Del Prette (2013) iniciam sua obra frisando a importância de se compreender o conceito de Habilidades Sociais (HS), cujo principal desempenho 
social é a competência social dos indivíduos (DEL PRETTE; DEL PRETTE, 2013). Neste sentido Del Prette e Del Prette (2013) assim definem as Habilidades Sociais:

[...] o termo Habilidades Sociais, geralmente utilizado no plural, aplica-se às diferentes classes de comportamentos sociais do repertório de um indivíduo, que contribuem para a competência social, favorecendo um relacionamento saudável e produtivo com as demais pessoas. (DEL PRETTTE; DEL PRETTE, 2013, p.31).

Bandeira, Marina et al. (2006) Considera que as HS mudam conforme a escolaridade dos pais e o nível socioeconômico, quanto maior a escolaridade dos pais e seu nível socioeconômico, maior o escore das HS; quanto menor a importância atribuída pelos pais às HS, menores os escores das crianças (BANDEIRA, Marina et al., 2006).

Oliveira e Silva (2013), em seus estudos sobre as HS afirmam que Almir e Zilda Del Prette são considerados os autores precursores do campo das HS no Brasil, produzindo grande parte do acervo científico nacional e sendo "responsáveis pela maior parte da disseminação dos conceitos teóricos e práticos da área do Treinamento de Habilidades Sociais" (OLIVEIRA; SILVA, 2013, p. 23).

Emidio, Ribeiro e De-Farias (2009) citam Del Prette e Del Prette (2005) em seu artigo clarificando o conceito de HS e sua implicância na vida social de crianças e adolescentes:

[...] um repertório pobre em habilidades sociais acarreta uma série de dificuldades interpessoais para a criança, incluindo: agressividade física e/ou verbal, comportamentos opositores ou desafiantes, condutas antissociais, depressão, isolamento social, ansiedade e fobia social. (DEL PRETTE; DEL PRETTE Op. Cit. EMIDIO, RIBEIRO; DE-FARIAS, 2009, p. 280)

Desta maneira as HS são importantes para a comunicação da criança, seja ela verbal ou não verbal, haja vista que:

\footnotetext{
[...] a criança aprende, desde cedo, que a escolha e o uso correto de determinadas palavras, em vez de outras, tem um efeito decisivo na interpretação que os demais fazem sobre o que quer comunicar. Por outro lado, aprende a inferir intenções e emoções com base no conteúdo verbal das mensagens que recebe. (DEL PRETTTE; DEL PRETTE,2013, p.37).
}

Percebe-se assim, pela audição não apenas o que interlocutor diz, mas o que ele realmente está querendo dizer (DEL PRETTTE; DEL PRETTE, 2009). Pela comunicação não verbal é possível perceber alteração no olhar, nos gestos, fazendo assim que se perceba o que vai além da fala da criança.

Silva e Murta (2009) chama atenção para os déficits em HS em etapa de desenvolvimento como a infância e a adolescência que podem comprometer fases posteriores do ciclo vital: 
a melhora no desempenho de habilidades sociais constitui um fator de proteção à saúde e de desenvolvimento do indivíduo por favorecer o aumento da autonomia, da autoestima e do suporte social. Um desempenho social com habilidades sociais pode prevenir comportamentos de risco à saúde, já que pode tornar o adolescente capaz de decidir por si mesmo, de recusar convites danosos à sua saúde e de discordar do grupo em momentos de pressão para uso de drogas, por exemplo. Isso justifica a inserção do Treinamento em Habilidades Sociais (THS) em intervenções para a prevenção e promoção de saúde de adolescentes (SILVA; MURTA, 2009, p.137).

Sinay (2015) em sua obra defende de forma clara e direta que "os pais são a primeira fonte de educação, sobretudo a educação afetiva, emocional, espiritual e dos valores" (SINAY, 2015, p. 93), poderia acrescentar-se aqui, com total certeza, primeira fonte das HS. Segue ele: "na sociedade dos filhos órfãos, as tragédias que afetam as crianças não são fenômenos naturais nem avatares do insondável destino. Essa orfandade não é produto do azar e sim de um tipo de vínculo humano e de um modelo de vida que predomina na sociedade que formamos. Um modelo cujo questionamento é urgente." (SINAY, 2015, p. 55).

Sobre essa mudança social o sociólogo polonês Zygmunt Bauman (2004) expressa que "a definição romântica do amor como 'até que a morte nos separe' está decididamente fora de moda." (BAUMAN, 2004, p. 19) Segue ele mais a frente "em vez de haver mais pessoas atingindo mais vezes os elevados padrões do amor, esses padrões foram rebaixados." (BAUMAN, 2004, p. 19)

Na mesma linha de pensamento Sganzerla e Levandowski (2010) afirmam que a "pós-modernidade é caracterizada por aceleradas transformações, especialmente no âmbito econômico, tecnológico e científico, o que repercute nos comportamentos e nas relações dos indivíduos." (SGANZERLA; LEVANDOWSKI, 2010, p. 296).

Bandeira et al. em seu artigo defendem a ideia que quanto maior a escolaridade dos pais e seu nível socioeconômico, maior o escore das habilidades sociais; quanto menor a importância atribuída pelos pais às habilidades sociais, menores os escores das crianças. O nível de habilidades sociais das crianças variou, portanto, em função de características sociodemográficas e sociais. (BANDEIRA, 2006, p. 541) Já Sinay (2015) afirma que a "orfandade não é um fenômeno dos marginalizados sociais, das classes baixas, de um mundo distante. Os filhos órfãos são uma legião e estão entre nós, ao nosso lado." (SINAY, 2015, p. 29).

Discordando dos demais autores Montecelli (2008) argumenta em seu artigo que "a ausência paterna não estaria associada ao comportamento delinquente dos filhos" (MONTECELLI, 2008, p. 94). Todavia, percebe-se através de estudos que o 
comportamento delinquente foi percebido com mais frequência em famílias que apresentavam ausência da figura paterna (MONTECELLI, 2008).

Sobre orfandades e ausência paterna Cúnico e Arpini (2014) discorrem: interessa destacar que o conceito de ausência paterna possui mais de uma definição. Uma delas diz respeito a ausência afetiva do pai (ou pais, que é a que defende Sinay), ou seja, é decorrente da distância emocional entre pai e filho, que pode ser decorrente de uma separação conjugal, morte e/ou trabalho do pai em outra cidade. Nesse caso, não se tem a presença física do genitor.

Por sua vez, Sganzerla e Levandowski (2010) chamam atenção para um problema decorrente da ausência física, que pode, com o tempo, resultar em distância afetiva entre pai-filho.

De modo geral, com base nos estudos revisados, percebe-se que a falta de envolvimento do pai na vida dos filhos adolescentes, decorrente de sua ausência prolongada ou definitiva, traz repercussões negativas para 0 desenvolvimento destes, tanto diretamente, por seus efeitos no âmbito pessoal, como indiretamente, pelos efeitos no funcionamento familiar (SGANZERLA; LEVANDOWSKI, 2010, p. 302).

Lopes e de Paula (2011) constatam a falta de estudos na área da ausência paterna e, por outro lado, concluem que muito se fala sobre a estima da figura paterna no desenvolvimento da criança e do adolescente, de que a presença do pai é de extrema importância no desenvolvimento das HS nas crianças e adolescentes (LOPES; DE PAULA, 2011).

Eizirik e Bergmann (2004) ousam afirmar que a ausência paterna geralmente tem um impacto negativo em crianças e adolescentes, sendo que estes estariam em maior risco para desenvolver problemas de comportamento (EIZIRIK; BERGMANN, 2004).

Na mesma linha de pensamento de Sinay (2015), Baumann (2004) e Sganzerla e Levandowski (2010) Benczik (2011) afirma que o papel do pai na sociedade vem passando por mudança e até se transformado.

De fato, a 'condição' de Pai evoluiu e continua em franco processo de evolução, devido as transformações culturais, sociais e familiares, passando pela fase em que os filhos eram propriedade do pai (com as mães quase sem direitos), e pela fase em que o pai era apenas o suporte financeiro da família (BENCZIK, 2011, p. 68).

É reconhecido e inegável o papel do pai no desenvolvimento da criança e a iteração entre pai e filho é um dos fatores decisivos para o desenvolvimento cognitivo e social e para adquirir as HS (BENCZIK, 2011). Citando Ferrari (1999) o autor afirma 
que o "vazio promovido pela ausência do pai é formado pela noção das crianças de não serem amadas pelo genitor que está ausente, com uma grande desvalorização de si mesmo, em consequência disso (FERRARI, Apud. BENCZIK, 2011).

Gadotti (2003) citando Kafka postula que o "amor" paterno está carregado de prepotência e de desprezo e egoísmo, de "um tirano cujos direitos estão baseados na sua pessoa e não na sua razão" (KAFKA, Apud. GADOTTI, 2003, p. 33). Segue ainda o autor

[...] um pai pode tornar-se um tirano. É um processo, evidentemente, motivado por circunstâncias nas quais está incluída a alienação do trabalho e o desejo de "vencer na vida", um processo que se constrói ao longo dos anos, inconscientemente. Desaparece o amor. Tudo se transforma em manipulação, sedução ou constrangimentos. E quando esse método falha só resta a força física para reduzir o filho a nulidade (GADOTTI, 2003, p. 34).

Continua Gadotti (2003), "a relação de pais e filhos é uma relação dialética, isto é, uma relação de unidade e de oposição ao mesmo tempo" (GADOTTI, 2003, p. 44). É uma relação contraditória, uma relação educadora.

Quando há lacunas deste sentido é preciso a intervenção de um profissional, por isso Emidio, Ribeiro e de-Farias (2009) chamam a atenção para "um dos principais objetivos da terapia infantil é implementar novas habilidades no repertório comportamental da criança de forma a possibilitar a sua melhor adaptação" (EMIDIO, RIBEIRO; DE-FARIAS, 2009, p. 367-368).

Por fim Patias et al. (2012) mostra que a ausência paterna desde o momento da gestação gera problemas de dificuldades familiares, por outro lado, onde não há essa ausência há um bom relacionamento entre os pais e filhos, diálogo, valorização e maior gama de HS (PATIAS et al. 2012).

\section{CONSIDERAÇÕES FINAIS}

Concluir um trabalho é sempre momento de olhar para trás e perceber o quanto mais se poderia ter feito e não se fez, seja por falta de tempo, seja por falta de material.

Esta pesquisa buscou explicitar as consequências da ausência paterna para a formação das habilidades sociais em adolescentes. Ao longo do trabalho alguns conceitos foram ficando mais claros, como por exemplo: ausência física e ausência emocional dos pais em relação aos filhos. 
Ficou claro que as famílias nas quais a ausência física dos pais se faz presente, seja por morte, seja por afastamento dos mesmos, os adolescentes desenvolvem déficits maiores de Habilidades Sociais, sendo difícil o convívio muitas vezes.

Por outro lado, quando os pais estão em casa, mas as casas não são verdadeiramente família, nas quais se trocam presença por presentes, se trocam afetos por benefícios, se percebe um coeficiente quando de adolescentes e jovens órfãos de pais vivos, com as mesmas dificuldades para ter uma boa gama de Habilidades sociais.

Esta pesquisa nos leva a pensar que o grave problema social, ou seja, abandono dos pais em relação aos filhos, seja por negligência em assumir a paternidade física, seja por não competência em assumir a paternidade emocional está gerando uma geração inteira de crianças e adolescentes mimados e rebeldes, incapazes de conviver socialmente e consequentemente uma geração inteira de despreparados para a vida, sem ânimo ou vontade de assumir seus atos e, ainda mais, sem sentido na sua existência.

Sendo assim, o que fazer para que treinar pais a serem mais presentes? Este não era o objetivo deste estudo, todavia ficou claro que se precisa ter um estudo mais aprofundado de treinamento de habilidades sociais nos pais, antes mesmo de se pensar nos adolescentes.

Outro questionamento que se levanta é sobre o círculo vicioso da vida humana, no qual os pais reproduzem nos filhos o aquilo que viveram com seus pais, e assim por diante. Quando iremos romper este círculo, no tocante as habilidades sociais, tendo jovens bem formados socialmente que possam educar seus filhos a terem melhores habilidades?

Ao chegarem nas séries escolares iniciais é comum educadores queixarem-se da falta das habilidades sociais das crianças, habilidades estas que mesmo na escola não conseguem apreender, pois não possuem respaldo e exemplo em suas casas. Assim, a falha em estabelecer limites, a relação conflitiva com os filhos ou a ausência sentimental ou física dos pais são algumas das condições que contribuem para o estabelecimento de um déficit de habilidades sociais.

\section{REFERÊNCIAS}

BANDEIRA, Marina et al. Habilidades sociais e variáveis sociodemográficas em estudantes do ensino fundamental. Psicologia em estudo, Maringá, v. 11, n. 3, p. 
541-549, dez.

2006.

Disponível

em:

<http://www.scielo.br/scielo.php?script=sci_arttext

\&pid=S141373722006000300010\&lng=pt\&nrm=iso>. Acesso em: 01 mar. 2016

BAUMAN, Zygmunt. Amor Líquido: Sobre a fragilidade dos laços humanos. Rio de Janeiro, RJ: Zahar, 2004.

BENCZIK, Edyleine Bellini Peroni. A importância da figura paterna para 0 desenvolvimento infantil. Revista Psicopedagogia, São Paulo, v. 28, n. 85, p. 67-75, 2011. Disponível em: <http://pepsic.bvsalud.org/scielo.php?script=sci_arttezt\&pid=S $010384862011000100007 \& \operatorname{lng}=$ pt\&nrm=iso $>$. Acesso em: 01 mar. 2016.

CUNICO, Sabrina Daiana; ARPINI, Dorian Mônica. Não basta gerar, tem que participar? um estudo sobre a ausência paterna. Revista Psicologia: Ciência e Profissão; Brasília, v. 34, n. 1, p. 226-241, mar. 2014. Disponível em: $<$ http://www.scielo.br/scielo.php?script

=sci_arttext\&pid=S141498932014000100016\&Ing=pt\&nrm=iso>. Acesso em: 22 fev. 2016.

DEL PRETTE, Zilda Aparecida Pereira; DEL PRETTE, Almir. Um sistema de categorias de habilidades sociais educativas. Paidéia (Ribeirão Preto), Ribeirão Preto, v. 18, n. 41, p. 517-530, dez. 2008. Disponível em: <http://www.scielo.br/scielo.php?script=sci_arttext\&pid=S0103863X2008000300008 \&lng=pt\&nrm=iso $>$. Acesso em: 01 mar. 2016.

DEL PRETTE, Zilda A. P.; DEL PRETTE, Almir. Psicologia das habilidades sociais: diversidade teórica e suas implicações. Petrópolis, RJ: Vozes, 2009.

DEL PRETTE, Zilda A. P.; DEL PRETTE, Almir. Psicologia das habilidades sociais na infância: teoria e prática. Petrópolis, RJ: Vozes, 2013.

EIZIRIK, Mariana; BERGMANN, David Simon. Ausência paterna e sua repercussão no desenvolvimento da criança e do adolescente: um relato de caso. Revista de psiquiatria, Porto Alegre, v. 26, n. 3, p. 330-336, dez. $2004 . \quad$ Disponível em: <http://www.scielo.br/scielo.php?script=sci_arttext\&pid=S010181082004000300010\& Ing=pt\&nrm=iso>. Acesso em 22 fev. 2016.

EMIDIO, Lorena Archanjo de Souza; RIBEIRO, Michela Rodrigues; DE-FARIAS, Ana Karina C. R. Terapia infantil e treino de pais em um caso de agressividade. Revista Brasileira de Terapia Comportamental e Cognitiva, Campinas-SP, 2009, Vol. XI, no 2, 366-385. Disponível em: < http://www.usp.br/rbtcc/index.php/RBTCC/article/view/410/304>. Acesso em 11 abr. 2016.

GADOTTI, Moacir. Dialética do amor paterno. 6 ed. São Paulo, SP: Cortez, 2003.

LOPES, Sandra Ribeiro de Almeida; DE PAULA, Sabrina Ferreira. A importância da figura paterna no processo de escolha profissional: um estudo comparativo entre jovens universitários. Psicologia: Teoria e Prática. São Paulo, 2011. Disponível em: <http://pepsic.bvsalud.org/pdf/ptp/v13n1/v13n1a13.pdf>. Acesso em 05 abri. 2016 
MONTICELLI, Fernanda Ferreiro. Efeitos da ausência paterna na aprendizagem. ETD - Educação Temática Digital, Campinas, v.10, n.1, p.87-104, dez. 2008 - ISSN: 1676-2592. Disponível em: <https://www.fe.unicamp.br/revistas/ged/etd/article /viewFile/1830/1672. Acesso em: 01 mar. 2016

PATIAS, Naiana Dapieve; DIAS, Ana Cristina Garcia; MAHL, Fernanda Donato e FIORIN, Pascale Chechi. Práticas educativas parentais e gestação na adolescência: comparando as experiências da gestante adolescente e da adolescente sem experiência de gestação. Adolescência e Saúde, Rio de Janeiro, v. 9, n. 1, p. 18-24, jan/mar 2012. Disponível em: <http://pepsic.bvsalud.org/scielo.php?script=sci_arttext \&pid=S0104-12822015000200002\&lng=pt\&nrm=iso >. Acesso em: 11 abr. 2016.

OLIVEIRA, Raquel Mendonça de; SILVA, Rosângela Braga da Cunha. Habilidades Habilidades Sociais: um estudo bibliométrico sobre os avanços deste campo no Brasil. UNIPAC: Universidade Presidente Antônio Carlos, 2013. Disponível em: <http://www.unipac.br/site/bb/tcc/tcc-582d92987050cc2795989b2f7f1e80ac.pdf>. Acesso em: 05 abr. 2016.

SGANZERLA, Ilciane Maria; LEVANDOWSKI, Daniela Centenaro. Ausência paterna e suas repercussões para 0 adolescente: análise da literatura. Psicologia em Revista, Belo Horizonte, v. 16, n. 2, p. 295-309, ago. 2010. Disponível em: $<$ http://pepsic.bvsalud .org/scielo.php? script=sci_arttext\&pid=S167711682010000200005\&lng=pt\&nrm=iso > Acesso em: 01 mar. 2016.

SILVA, Mariana de Paula e; MURTA, Sheila Giardini. Treinamento de habilidades sociais para adolescentes: uma experiência no programa de atenção integral à família (PAIF). Psicologia: Reflexão e Crítica, Porto Alegre, v. 22, n. 1, p. 136-143, 2009. Disponível em: <http://www.scielo.br/scielo.php?script=sci_arttext\&pid=S0102$79722009000100018 \&$ lng=pt\&nrm=iso >. Acesso em: 22 fev. 2016.

SINAY, Sergio. A sociedade dos filhos órfãos: quando pais e mães abandonam suas responsabilidades. 2 ed. Rio de Janeiro, RJ: BestSeller, 2015. 